\title{
Flavanone plasma pharmacokinetics from blood orange juice in human subjects
}

\author{
Claudio Gardana, Serena Guarnieri, Patrizia Riso, Paolo Simonetti* and Marisa Porrini \\ DiSTAM - Department of Food Science and Microbiology, Division of Human Nutrition, University of Milan Via Celoria 2, 20133 \\ Milan, Italy \\ (Received 27 November 2006 - Revised 17 January 2007 - Accepted 18 January 2007)
}

\begin{abstract}
Some blood orange juice (BOJ) flavanones may have antioxidant, anti-inflammatory, anti-allergic, hypolipidaemic, vasoprotective and anticarcinogenic properties. The aim of the present study was to evaluate the pharmacokinetics of hesperetin and naringenin in human subjects after BOJ intake. In a cross-over study, seven healthy female volunteers consumed 150 and $300 \mathrm{ml}$ BOJ corresponding to about 51-102 mg hesperetin and to 6-12 mg naringenin, respectively. Plasma samples were collected before, each hour for $8 \mathrm{~h}$ and $24 \mathrm{~h}$ after BOJ administration and analysed for their content of hesperetin and naringenin by liquid chromatography-MS/MS. The plasma concentrations of these compounds were dose dependent and the peak concentration $\left(C_{\max }\right)$ was reached in 5.1 (SD 0.6) h after BOJ intake. The $C_{\max }$ of hesperetin was 43.4 (SD 32.4 ) and 79.8 (SD 60.1) ng/ml after 150 and $300 \mathrm{ml}$ intake, respectively. For naringenin the plasma peak was 16.4 (SD 11.9) and 34.0 (SD 20.6) ng/ml. Moreover, the conjugated forms of these flavanones represent more than $95 \%$ of the plasma concentration. The results indicate that both hesperetin and naringenin are bioavailable after BOJ intake; naringenin seemingly more so than hesperetin.
\end{abstract}

Flavanones: Blood orange juice: Pharmacokinetics: Human studies

Flavonoids are important micronutrients present in the human diet, and in the past decade an increasing number of studies regarding the positive effects on human health of these natural compounds have been reported (Le March, 2002; Morrissey \& Watson, 2003; Manach et al. 2005a; Scalbert et al. 2005). Good sources of these compounds are citrus fruit juices obtained from oranges and grapefruit. These fruits and their beverages contain mainly the flavanones hesperidin (hesperetin-7-rutinoside) and narirutin (naringenin-7-rutinoside) (Tomas-Barberan \& Clifford, 2000) and lesser amounts of anthocyanins and carotenoids when the juice is obtained from blood oranges.

The hesperidin and narirutin ingested with the food are metabolised by human intestinal bacterial microflora to the aglycones hesperetin and naringenin, respectively (Choudhury et al. 1999; Felgines et al. 2000; Matsumoto et al. 2004).

These compounds possess antioxidant (Heo et al. 2004; Hirata et al. 2005), anticarcinogenic (Shen et al. 2004), hepatolipidaemic (Kurowska \& Manthey, 2004) and anti-inflammatory (Rotelli et al. 2003) activities. In addition, naringenin and hesperetin are phyto-oestrogens. In fact, like isoflavones, they can bind to oestrogen receptors (Harris et al. 2005), or inhibit aromatase activity, the rate-limiting enzyme in the conversion of androgens to oestrogens (Edmunds et al. 2005).

Recently, a study was carried out (Riso et al. 2005) supplementing human volunteers for $21 \mathrm{~d}$ with blood orange juice (BOJ) to evaluate its effect on plasma antioxidant concentrations and on DNA damage and lipid peroxidation. The results revealed an improvement of lymphocyte DNA resistance to oxidative stress after BOJ intake. Despite these welldocumented effects on human health the information about naringenin and hesperidin bioavailability in human subjects after BOJ intake is poor. In fact, the pharmacokinetics of these flavanones has been studied using mainly juices obtained from blond oranges and grapefruits (Erlund et al. 2001; Manach et al. 2003). Moreover, these studies were performed using high amounts of juice or pure compounds (Kanaze et al. 2006).

The aim of the present study was to evaluate by liquid chromatography (LC)-MS/MS the plasma pharmacokinetics of naringenin and hesperetin after the intake of low amounts of BOJ.

\section{Subjects and methods}

Chemicals

Naringin, narirutin, hesperidin, didymin, morin, naringenin and hesperetin were from Extrasynthese (Genay, France). $\beta$-Glucuronidase-sulfatase from Helix pomatia was purchased from Sigma (St Louis, MO, USA). Methanol, acetonitrile, sodium and ammonium acetate were from Merck (Darmstadt, Germany). Water was obtained from a MilliQ apparatus (Millipore, Milford, MA, USA). The squeezed and pasteurised BOJ from organic culture was obtained

\footnotetext{
Abbreviations: AUC, area under the curve; BOJ, blood orange juice; $C_{\max }$, peak concentration; I.S., internal standard; LC, liquid chromatography.

* Corresponding author: Professor Paolo Simonetti, fax +39 02 50316071, email Paolo.Simonetti@unimi.it
} 
from Fattoria Scaldasole (Monguzzo, Italy). The orange juice had been produced from oranges (Citrus sinensis) of the cultivars Tarocco and Sanguinello. The BOJ used was portioned in $500 \mathrm{ml}$ containers which were stored at $-20^{\circ} \mathrm{C}$. After the containers were thawed, the juices were immediately consumed.

\section{Subject and study design}

Healthy female subjects ( $n$ 7; age $25.7 \pm 1.1$ years; BMI $16 \cdot 2-21.8 \mathrm{~kg} / \mathrm{m}^{2}$ ) were selected after completing a questionnaire concerning their dietary habits and lifestyle. They were not taking any supplement, drug or medication. Informal, written consent was obtained from each participant and the local ethical committee approved the protocol. Volunteers refrained from consuming citrus fruits or juices for $1 \mathrm{~d}$ before the study. On the day of the experiment subjects were confined to the laboratory. Between 08.30 and 09.00 hours the fasted volunteers received 150 and $300 \mathrm{ml}$ of BOJ in random order on two occasions 1 month apart. Lunch consisted of bread $(70 \mathrm{~g})$, cheese $(20 \mathrm{~g})$, ham $(50 \mathrm{~g})$, ice-cream $(80 \mathrm{~g})$ and decaffeinated coffee (one cup). The dinner consisted of pasta $(80 \mathrm{~g})$, olive oil $(10 \mathrm{~g})$, parmigiano cheese $(15 \mathrm{~g})$, meat $(100 \mathrm{~g})$, bread $(70 \mathrm{~g})$ and decaffeinated coffee (one cup). After dinner ( $8 \mathrm{~h}$ after BOJ intake), the volunteers were allowed to leave the laboratory, returning the next morning for the final blood sampling. Blood samples were collected in tubes containing lithiumheparin before, each hour for $8 \mathrm{~h}$ and $24 \mathrm{~h}$ after BOJ administration. Time zero was obtained $30 \mathrm{~min}$ before the juice ingestion.

\section{Flavanone determination in blood orange juice}

BOJ was diluted 10-fold in methanol:1 \% formic acid (90:10, $\mathrm{v} / \mathrm{v}$ ) and the resulting solution was sonicated for $10 \mathrm{~min}$ and centrifuged at $1000 \mathrm{~g}$ for $10 \mathrm{~min}$. One sample of the supernatant fraction was filtered through a Millipore $0.2 \mu \mathrm{m}$ disk; $5 \mu \mathrm{l}$ were used for analysis. The chromatographic system consisted of an Alliance model 2695 (Waters, Milford, MA, USA) equipped with a model 2996 (Waters) photodiode array detector and a triple quadrupole mass spectrometer model Quattro micro (Micromass, Beverly, MA, USA). A $3.5 \mu \mathrm{m} \mathrm{C} \mathrm{C}_{18}$ Symmetry column $(150 \times 2.1 \mathrm{~mm}$; Waters) was used for the separation, which was performed by means of a linear gradient elution (eluent A, $0.1 \%$ formic acid; eluent $\mathrm{B}$, acetonitrile) at a flow rate of $250 \mu \mathrm{l} / \mathrm{min}$. The column was maintained at $30^{\circ} \mathrm{C}$. The gradient was as follows: from 10 to $30 \% \mathrm{~B}$ in $20 \mathrm{~min}$ and then from 30 to $60 \% \mathrm{~B}$ in $10 \mathrm{~min}$. Chromatographic data were acquired in the $200-450 \mathrm{~nm}$ range and were integrated at $290 \mathrm{~nm}$. The mass spectrometer operated in full-scan mode in the range $100-1000 \mathrm{Da}$. All data were acquired by Masslink 4.0 software (Micromass). The flavanone concentrations were evaluated in six different BOJ containers, and each analysis was carried out in triplicate.

Calibration curves were obtained from narirutin, naringin, didymin, hesperidin, naringenin and hesperetin stock solutions prepared by dissolving $5 \mathrm{mg}$ of standard powder in $5 \mathrm{ml}$ methanol. They were measured in the range of $2-100 \mu \mathrm{g} / \mathrm{ml}$.

\section{Analysis of hesperetin and naringenin in plasma}

Hesperetin and naringenin conjugates were hydrolysed by incubating $100 \mu \mathrm{l}$ heparinised plasma with $50 \mu \mathrm{l}$ internal standard (I.S.) (morin; $100 \mathrm{ng} / \mathrm{ml})$ in $0.1 \mathrm{M}-\mathrm{CH}_{3} \mathrm{COONa}$ buffer $(\mathrm{pH}$ $5 \cdot 2)$ and $100 \mu \mathrm{l}$ glucuronidase-sulfatase $(1 \mathrm{U} / \mu \mathrm{l})$ at $37^{\circ} \mathrm{C}$ for $18 \mathrm{~h}$. The reaction mixture was extracted with $500 \mu \mathrm{l}$ ethylacetate, vortexed and centrifuged at $1000 \mathrm{~g}$ for $1 \mathrm{~min}$. The supernatant fraction $(400 \mu \mathrm{l})$ was dried under $\mathrm{N}_{2}$ and the residue dissolved in $100 \mu \mathrm{l}$ methanol. To evaluate free hesperetin and naringenin, a plasma sample $(100 \mu \mathrm{l})$ was incubated with $50 \mu \mathrm{l}$ I.S. and $100 \mu \mathrm{l}$ of $0 \cdot 1 \mathrm{M}-\mathrm{CH}_{3} \mathrm{COONa}$ buffer $\left(\mathrm{pH} \mathrm{5.2)}\right.$ for $18 \mathrm{~h}$ at $37^{\circ} \mathrm{C}$. The reaction mixture was then treated as described earlier.

The HPLC system was an Alliance 2695 (Waters) coupled to a Quattro Micro triple quadrupole mass spectrometer equipped with an electrospray source operating in negative mode. The analytical column was a $3.5 \mu \mathrm{m}$ Symmetry $(150 \times 2 \cdot 1 \mathrm{~mm})$ and the flow rate was fixed to $250 \mu \mathrm{l} / \mathrm{min}$. The eluent was $2 \mathrm{~mm}_{-} \mathrm{CH}_{3} \mathrm{COONH}_{4} \quad(\mathrm{pH}$ 5):acetonitrile $(70: 30, v / v)$. The injected volume was $10 \mu l$. The capillary voltage was set to $3.0 \mathrm{kV}$, the cone voltage was $40 \mathrm{~V}$, the source temperature was $130^{\circ} \mathrm{C}$, and the desolvating temperature was $350^{\circ} \mathrm{C}$. The collision energy was $35 \mathrm{eV}$, and Argon $6 \cdot 0$ (Sapio, Monza, Italy) was used at $2.2 \times 10^{-3}$ mbar to improve fragmentation in the collision cell. Naringenin and hesperetin plasma levels were determined in multiple reaction-monitoring mode. The calibration curves were in the range of $2-100 \mathrm{ng} / \mathrm{ml}$ and the detection limit was 0.5 and $1 \mathrm{ng} / \mathrm{ml}$ for naringenin and hesperetin, respectively.

\section{Assessment of matrix effect on flavanone assay in plasma}

The assessment of a matrix effect was evaluated as described by Matuszewski et al. (2003) Briefly, three sets of five standard lines $(2,10,25,50$ and $100 \mathrm{ng} / \mathrm{ml})$ were prepared to evaluate the assay accuracy, precision, recovery, and absence or presence of a matrix effect. The first set was prepared to evaluate the MS/MS response for naringenin, hesperetin and I.S. injected in the mobile phase. The second set was prepared in plasma extracts spiked after extraction. The third set was prepared in plasma spiked before extraction. The matrix effect on the quantification of flavanones and I.S. was assessed by comparing the absolute areas, peak areas ratios, and slopes of the standard lines between these three different sets. In addition, precision and accuracy of the method and recovery of analytes were also determined.

\section{Statistical analysis}

Statistical analyses were performed with the STATISTICA software (Statsoft Inc., Tulsa, OK, USA). A two-way repeated-measures ANOVA with the amount of juice and the time as the independent factor was used. The peak plasma concentration $\left(C_{\max }\right)$ and the time taken to reach peak concentrations are expressed as mean values and standard deviations.

The elimination rate constant $(K)$ was determined in the terminal phase from the slope of the regression line of the concentrations in plasma samples. Three time points, starting with the time taken to reach peak concentration, were included in 
the estimation of $K$. The terminal half-life was calculated as $0 \cdot 6935 / K$. Area under the curve (AUC) was calculated in the range $0-24 \mathrm{~h}$, although between 8 and $24 \mathrm{~h}$ there was no plasma sample, according to the following equation:

$$
\begin{aligned}
\text { Area }= & (1 / 2)\left(C_{0}+C_{1}\right)\left(t_{1}-t_{0}\right)+(1 / 2)\left(C_{1}+C_{2}\right)\left(t_{2}-t_{1}\right) \ldots \\
& +(1 / 2)\left(C_{8}+C_{24}\right)\left(t_{24}-t_{8}\right),
\end{aligned}
$$

where $C$ is flavanone concentration and $t$ denotes time.

\section{Results}

The content of flavanones in blood orange juice

Fig. 1 shows a typical LC-diode-array detection MS (LCDAD-MS) chromatogram of BOJ. Narirutin and hesperidin eluted at about $16 \cdot 3$ and $17.9 \mathrm{~min}$, respectively. Their identity was established by co-chromatography, 'on-line' UV spectra comparison and molecular ion evaluation. Peak 3 shows a UV spectrum suggesting a structure of a flavanone derivative. MS of peak 3 yielded a negative ion at $m / z$ 593, and a product ion at $\mathrm{m} / \mathrm{z}, 285$, suggesting that it may contain an aglycone moiety. Aglycones (peaks 5 and 6) were not present in BOJ. The content of hesperidin and narirutin in BOJ was 68.6 (SD 1.9) and 8.2 (SD 0.6) $\mathrm{mg} / 100 \mathrm{ml}$, respectively. The peak 3 concentration was $10 \cdot 3(\mathrm{SD} 0 \cdot 5) \mathrm{mg} / 100 \mathrm{ml}$. Naringin was not found in the analysed BOJ. Thus, the ingestion of 150 or $300 \mathrm{ml}$ of BOJ provided 51.3 (SD 0.9) or 102.4 (SD 1.8) $\mathrm{mg}$ hesperetin and $5.9(\mathrm{SD} 0.2)$ or 11.8 (SD 0.4) $\mathrm{mg}$ naringenin, respectively. The detection limit was about $1 \mu \mathrm{g} / \mathrm{ml}$ for both hesperidin and narirutin. The overall reproducibility of quantitative analysis of narirutin and hesperidin was 2.3 (SD 0.2) and 3.2 (SD 0.4) \% for intra- and inter-day analysis, respectively. Moreover, BOJ flavanones were stable over 6 months when stored at $-20^{\circ} \mathrm{C}$ in a closed brik.

\section{Analysis of flavanones in plasma}

Under the applied conditions, naringenin and hesperetin were separated in less than $13 \mathrm{~min}$, and their plasma concentrations calculated by external standardisation from calibration curves. Hesperetin and naringenin plasma levels were evaluated after hydrolysis of samples by $\beta$-glucuronidase-sulfatase. The conjugated forms of these flavanones represent more than $95 \%$ of the plasma forms. None of the subjects had detectable amount of naringenin or hesperetin at baseline.

Fig. 2 shows an example of naringenin and hesperetin peaks detected by LC-MS/MS in an enzymically hydrolysed plasma sample obtained after 0 and $5 \mathrm{~h}$ of BOJ intake. Mean naringenin and hesperetin plasma levels following the intake of 150 and $300 \mathrm{ml} \mathrm{BOJ}$ are reported in Table 1. ANOVA showed a significant effect of time $(P<0.0001)$ and the amount of BOJ consumed on the absorption of naringenin $(P=0.022)$ and hesperetin $(P=0 \cdot 006)$.

Fig. 3 shows naringenin and hesperetin plasma levels in all subjects after BOJ intake. The compounds were absorbed by all subjects but there were great inter-individual differences in the $\mathrm{AUC}_{(0-24 \mathrm{~h})}$ and $C_{\max }$ values. Flavanones at baseline were not detected. The highest plasma level $\left(C_{\max }\right)$ of naringenin and hesperetin was reached $5-6 \mathrm{~h}$ after the BOJ ingestion; these levels decreased significantly after $8 \mathrm{~h}$. At $24 \mathrm{~h}$ after BOJ intake flavanones were no longer detectable in plasma.

The $C_{\max }$ of hesperetin was 43.4 (SD 32.4) and 79.8 (SD $60 \cdot 1) \mathrm{ng} / \mathrm{ml}$ after 150 and $300 \mathrm{ml}$ BOJ intake, respectively. For naringenin the peak plasma was 16.4 (SD 11.9) and 34.0 (SD 20.6) $\mathrm{ng} / \mathrm{ml}$. Table 2 summarises the individual and group mean values of the kinetics indexes calculated from the flavanone plasma levels and expressed as apparent pharmacokinetics measured as AUC and dose adjusted (AUC/ dose). In particular, after the $300 \mathrm{ml}$ portion, significantly higher levels of hesperetin and naringenin were observed after 5 and $4 \mathrm{~h}$, respectively, with respect to the $150 \mathrm{ml}$ portion.

The hesperetin half-life was $1 \cdot 1(\mathrm{SD} 0 \cdot 5)$ and $1.0(\mathrm{SD} 0 \cdot 5) \mathrm{h}$ for 150 and $300 \mathrm{ml}$ BOJ intake, respectively. For naringenin the half-life was 1.3 (SD 1.0) and 0.9 (SD 0.4) $\mathrm{h}$ for $150 \mathrm{ml}$ and $300 \mathrm{ml}$ of BOJ intake, respectively.

\section{Percentage recovery of flavanones from plasma}

The recovery of the extraction for hesperetin, naringenin and I.S. from spiked plasma samples was 94.2 (SD 3.2), 96.1 (SD 3.3 ) and 85 (SD 2.4) \%, respectively. The precision of the method was tested by both intra-day ( $n$ 6) and inter-day $(5 \mathrm{~d} ; n 6)$ reproducibility, and the $\mathrm{CV}$ was below $8 \%$.

\section{Discussion}

The aim of the present study was to establish hesperetin and naringenin pharmacokinetics after BOJ intake. To this end, we developed mass spectrometric methods for the analysis of hesperetin and naringenin in plasma sample and their glycosides in BOJ. In the present work, the negative ion electrospray ionisation mass spectrum of BOJ showed abundant ion peaks at $(\mathrm{m} / \mathrm{z})^{-} 579$ and $(\mathrm{m} / \mathrm{z})^{-} 609$, corresponding to narirutin and hesperidin, respectively. In BOJ, hesperidin and narirutin were the main flavanones present and their amount was estimated to be about 686 and $82 \mathrm{mg} / \mathrm{l}$, respectively. Moreover, a more apolar compound (peak 3; Fig. 1) was found. LC-electrospray ionisation-MS analysis of this unknown compound yielded an intense peak at $(\mathrm{m} / \mathrm{z})^{-}$593. MS/MS analysis of the $(\mathrm{m} / \mathrm{z})^{-} 593$ ion as precursor ion gave a product ion with $(\mathrm{m} / \mathrm{z})^{-} 285$. The mass data, combined with the UV and chromatographic behaviour, suggest that this peak is didymin (Robards et al. 1997). Peak identity was then confirmed by authentic standard.

From our data, a moderate BOJ intake $(300 \mathrm{ml})$ provides about $128 \mathrm{mg}$ flavanones. At this time no data regarding total flavonoid intake in Italy are available. In the USA the dietary polyphenol intake has been estimated to be about $1 \mathrm{~g} / \mathrm{d}$ (Kuhnau, 1976). Several subsequent studies have provided additional data concerning the intake of various classes of polyphenols (Justesen et al. 1997; Sampson et al. 2002), and the dietary flavonoid intake in Western countries is now estimated to be in the range $100-150 \mathrm{mg} / \mathrm{d}$ (Manach et al. 2004). In Italy, the only available data on flavonoid intake concerns the flavonols and has been estimated as about $35 \mathrm{mg} / \mathrm{d}$ (Pietta et al. 1996). The intake of $300 \mathrm{ml} \mathrm{BOJ,} \mathrm{conse-}$ quently, provides a significant amount of flavonoids, and can play a role against oxidative stress. 

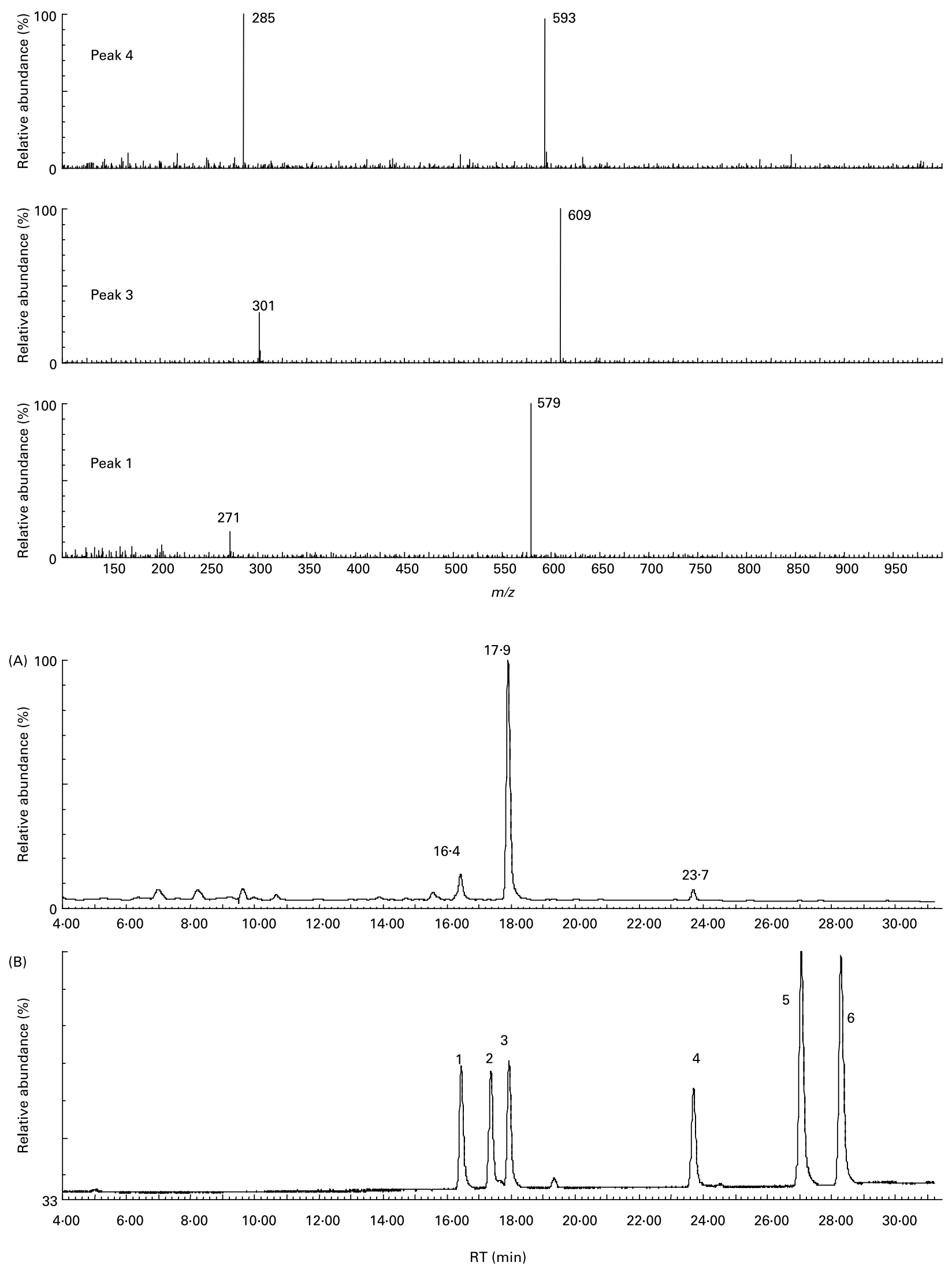

Fig. 1. Liquid chromatography-diode-array detection MS (LC-DAD-MS) chromatograms of blood orange juice (A) and standard solutions (B) at $290 \mathrm{~nm}$. Peak 1 represents narirutin (retention time (RT) $16.4 \mathrm{~min},(\mathrm{~m} / \mathrm{z})^{-}$579, 271 (aglycone). Peak 2 represents naringin (RT 17.2 min, not present in blood orange juice). Peak 3 represents hesperidin (RT $17.9 \mathrm{~min},(\mathrm{~m} / \mathrm{z})^{-}$609, 301 (aglycone)). Peak 4 represents didymin (RT $23.7 \mathrm{~min},(\mathrm{~m} / \mathrm{z})^{-} 593,285$ (ion product)). Peak 5 represents naringenin; peak 6 represents hesperetin. 

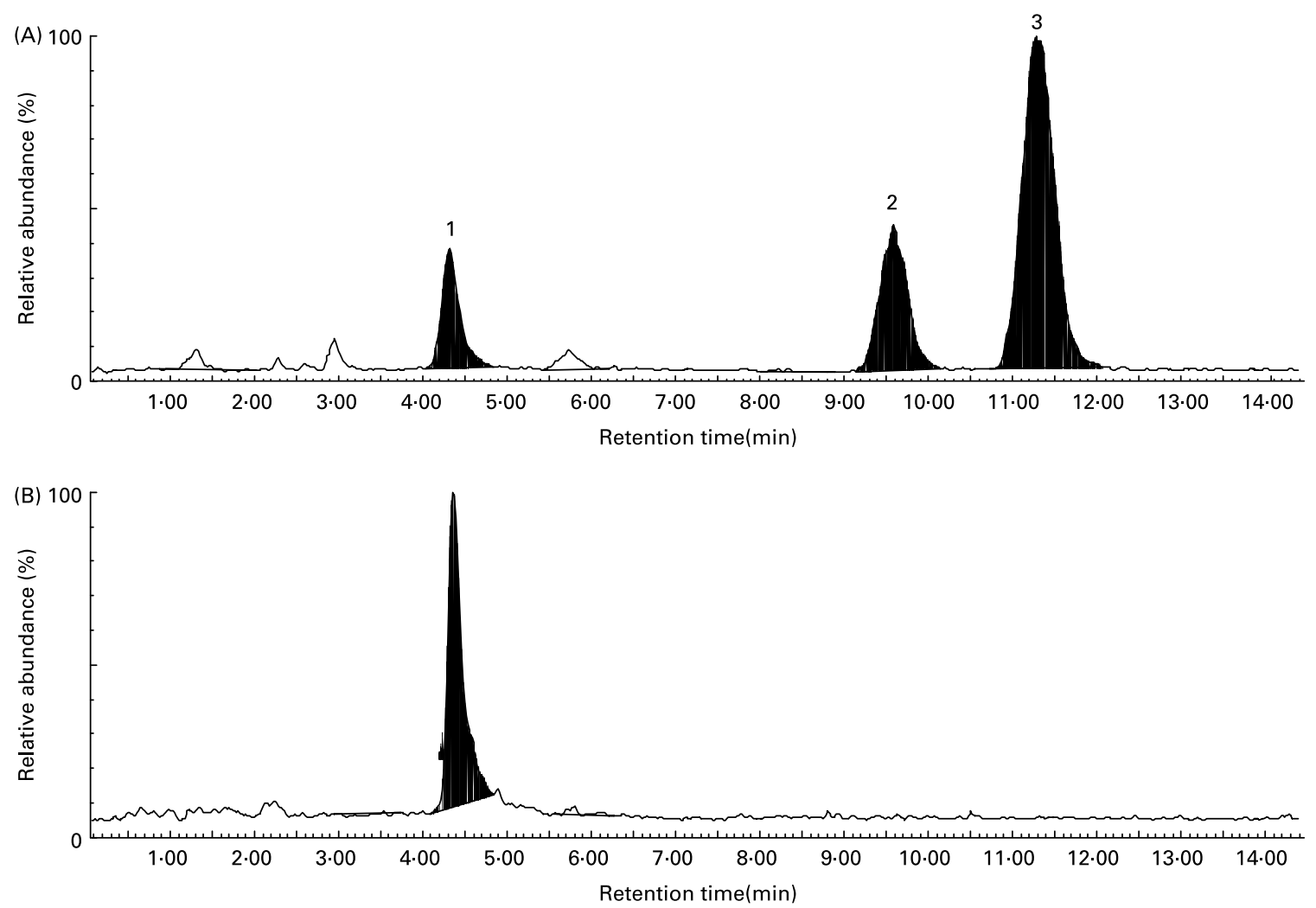

Fig. 2. Typical liquid chromatography (LC)-MS/MS chromatograms (multiple reaction monitoring mode) of a plasma sample (subject 3 ) collected $5 \mathrm{~h}$ after the intake of $300 \mathrm{ml}$ blood orange juice (A) and before intake (B). Peak 1 represents the internal standard (morin) (transition $\left.(\mathrm{m} / \mathrm{z})^{-} 301 \rightarrow 151\right)$. Peak 2 represents naringenin (transition $\left.(\mathrm{m} / \mathrm{z})^{-} 271 \rightarrow 151\right)$. Peak 3 represents hesperetin (transition $\left.(\mathrm{m} / \mathrm{z})^{-} 301 \rightarrow 164,(\mathrm{~m} / \mathrm{z})^{-} 301 \rightarrow 151\right)$.

In plasma, the electrospray ionisation negative collisionally activated dissociation MS (CAD-MS/MS) of naringenin gave a product ion with $(\mathrm{m} / \mathrm{z})^{-} 151$. The $(\mathrm{m} / \mathrm{z})^{-} 151$ is a common ion product for flavanones and is believed to result from the retro-Diels-Alder reaction of the flavonoid A ring. In the applied conditions, hesperetin also gave the product ion with $(\mathrm{m} / \mathrm{z})^{-} 151$ but the most abundant ion product was the ion with $(m / z)^{-} 164$.
Naringenin and hesperetin plasma concentrations were determined in multiple reaction monitoring mode using the transitions $(\mathrm{m} / \mathrm{z})^{-} 271 \rightarrow 151$ and $(\mathrm{m} / \mathrm{z})^{-} 301 \rightarrow 164,(\mathrm{~m} / \mathrm{z})^{-}$ $301 \rightarrow 151$, respectively. For morin (I.S.) we used the transition $(\mathrm{m} / \mathrm{z})^{-} 301 \rightarrow 151$.

The results show that naringenin and hesperetin were absorbed from BOJ by all the subjects. However, relevant inter-individual variations were observed as indicated by the

Table 1. Concentration of flavanones in plasma $(\mathrm{ng} / \mathrm{ml})$ before $(t=0)$ and after drinking 150 or $300 \mathrm{ml}$ blood orange juice (BOJ) (Mean values and standard deviations)

\begin{tabular}{|c|c|c|c|c|c|c|c|c|}
\hline \multirow[b]{3}{*}{$t(\mathrm{~h})$} & \multicolumn{4}{|c|}{ Hesperetin } & \multicolumn{4}{|c|}{ Naringenin } \\
\hline & \multicolumn{2}{|c|}{$300 \mathrm{ml}$} & \multicolumn{2}{|c|}{$150 \mathrm{ml}$} & \multicolumn{2}{|c|}{$300 \mathrm{ml}$} & \multicolumn{2}{|c|}{$150 \mathrm{ml}$} \\
\hline & Mean & SD & Mean & SD & Mean & SD & Mean & SD \\
\hline 0 & 0.0 & 0.0 & 0.0 & 0.0 & 0.0 & 0.0 & 0.0 & 0.0 \\
\hline 1 & 0.0 & 0.0 & 0.0 & 0.0 & 0.0 & 0.0 & 0.0 & 0.0 \\
\hline 2 & 4.4 & $7 \cdot 6$ & 1.4 & 3.8 & 1.2 & $2 \cdot 0$ & $1 \cdot 2$ & $3 \cdot 1$ \\
\hline 3 & 13.4 & $16 \cdot 6$ & $12 \cdot 8$ & $26 \cdot 2$ & 7.6 & $7 \cdot 0$ & 3.7 & 8.0 \\
\hline 4 & $36 \cdot 0$ & 38.6 & 23.9 & $37 \cdot 3$ & $16 \cdot 8$ & $17 \cdot 0$ & $10 \cdot 4$ & $14 \cdot 6$ \\
\hline 5 & $73 \cdot 2$ & $62 \cdot 2$ & 33.0 & $31 \cdot 6$ & 34.0 & $20 \cdot 6$ & $13 \cdot 4$ & $6 \cdot 8$ \\
\hline 6 & $55 \cdot 7$ & 37.6 & 33.2 & $27 \cdot 7$ & $13 \cdot 6$ & $9 \cdot 7$ & $7 \cdot 4$ & 4.5 \\
\hline 7 & 35.9 & 34.5 & $20 \cdot 5$ & $25 \cdot 7$ & 5.5 & 4.5 & $4 \cdot 1$ & 3.9 \\
\hline 8 & $24 \cdot 7$ & $40 \cdot 7$ & 8.4 & $11 \cdot 2$ & $2 \cdot 2$ & 2.9 & 1.7 & $2 \cdot 6$ \\
\hline 24 & 0.0 & 0.0 & 0.0 & 0.0 & 0.0 & 0.0 & 0.0 & 0.0 \\
\hline
\end{tabular}


(A)
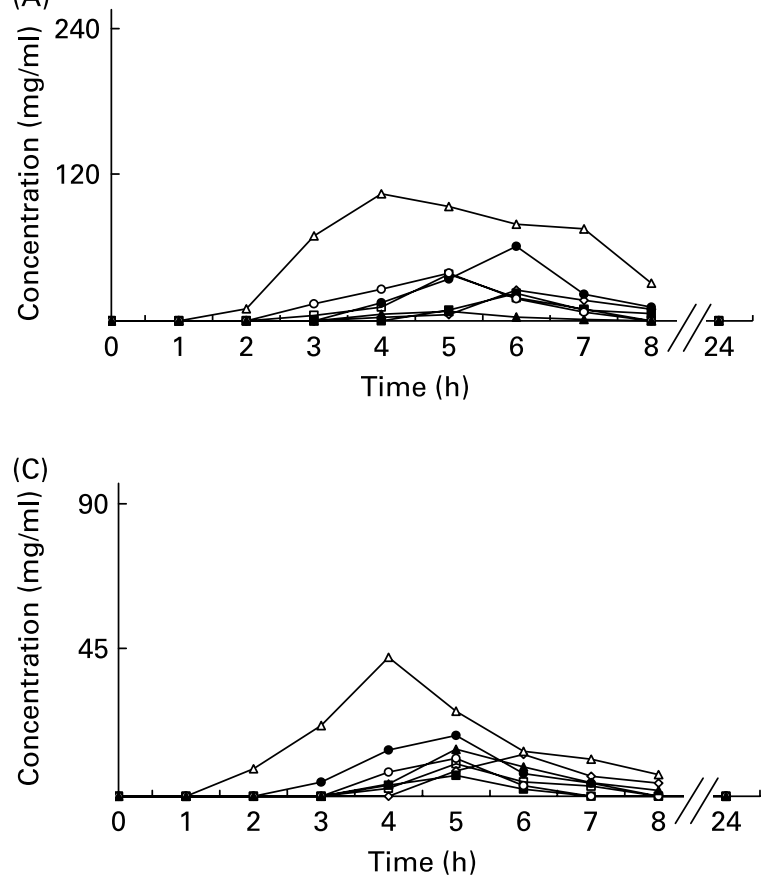

(B)
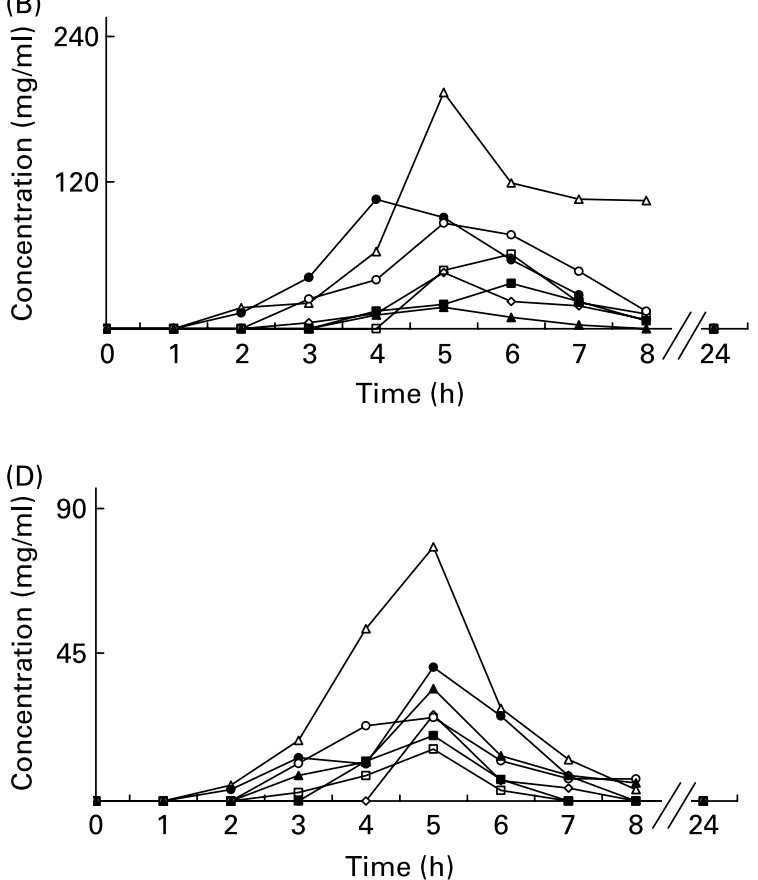

Fig. 3. Individual plasma concentration curves for hesperetin $(A, B)$ and naringenin $(C, D)$ after the consumption of $150 \mathrm{ml}(A, C)$ and $300 \mathrm{ml}(B, D)$ of blood orange juice. $(\diamond)$, Subject $1 ;(\square)$, subject $2 ;(\Delta)$, subject 3 ; $(\bullet)$, subject $4 ;(\square)$, subject 5 ; $(\bigcirc)$, subject 6 ; $(\boldsymbol{\Lambda})$, subject 7 .

high standard deviations in the $C_{\max }$ and AUC values (Table 2) in subjects receiving the same BOJ dose. The subjects were all female students with comparable age, weight and food habits. For these reasons, it seems that the inter-individual variability was not dependent on these parameters. As hypothesised by Erlund et al. (2001) these variations could be due to different gastrointestinal microflora composition. In fact, the intestinal human microflora would not be able to remove the sugar moiety or it may metabolise the aglycones into phenolic acids (Felgines et al. 2000). Recently, Nielsen et al. (2006) demonstrated that the bioavailability of hesperidin was modulated by the enzymic conversion to hesperetin-7-glucoside, changing the absorption site from the colon to the small intestine.

Table 2. Plasma kinetic indexes in healthy volunteers $(n 7)$ for hesperetin and naringenin after ingestion of 150 or $300 \mathrm{ml}$ of blood orange juice (Individual values, group mean values and standard deviations)

\begin{tabular}{|c|c|c|c|c|c|c|c|c|}
\hline \multirow[b]{2}{*}{ Subject } & \multicolumn{2}{|c|}{$t_{\max }(\mathrm{h})$} & \multicolumn{2}{|c|}{$C_{\max }(\mathrm{ng} / \mathrm{ml})$} & \multicolumn{2}{|c|}{$\begin{array}{c}\text { AUC } \\
(\mathrm{ng} \times \mathrm{h}) / \mathrm{ml}\end{array}$} & \multicolumn{2}{|c|}{$\begin{array}{l}\text { AUC/dose } \\
(\mathrm{ng} \times \mathrm{h}) / \mathrm{ml}\end{array}$} \\
\hline & $150 \mathrm{ml}$ & $300 \mathrm{ml}$ & $150 \mathrm{ml}$ & $300 \mathrm{ml}$ & $150 \mathrm{ml}$ & $300 \mathrm{ml}$ & $150 \mathrm{ml}$ & $300 \mathrm{ml}$ \\
\hline \multicolumn{9}{|c|}{ Hesperetin } \\
\hline 1 & 6 & 5 & $25 \cdot 6$ & $46 \cdot 9$ & $133 \cdot 3$ & $170 \cdot 8$ & $2 \cdot 6$ & $1 \cdot 7$ \\
\hline 2 & 6 & 6 & 22.9 & 37.9 & 93.6 & $151 \cdot 2$ & $1 \cdot 8$ & 1.5 \\
\hline 3 & 4 & 5 & 106.0 & 197.5 & 702.9 & 1433.1 & 13.7 & $14 \cdot 0$ \\
\hline 4 & 6 & 4 & $62 \cdot 3$ & $108 \cdot 1$ & $231 \cdot 1$ & $336 \cdot 1$ & 4.5 & $3 \cdot 3$ \\
\hline 5 & 5 & 6 & 33.8 & $62 \cdot 2$ & 83.6 & 237.4 & 1.6 & $2 \cdot 3$ \\
\hline 6 & 5 & 5 & 39.9 & $88 \cdot 2$ & $106 \cdot 0$ & 404.4 & $2 \cdot 1$ & 3.9 \\
\hline 7 & 5 & 5 & $7 \cdot 8$ & 17.9 & $17 \cdot 8$ & 41.8 & 0.3 & 0.4 \\
\hline Mean & 5.3 & $5 \cdot 1$ & 43.4 & $79 \cdot 8$ & 195.5 & 396.4 & $3 \cdot 8$ & $3 \cdot 8$ \\
\hline SD & 0.8 & 0.7 & $32 \cdot 4$ & $60 \cdot 1$ & $232 \cdot 7$ & $472 \cdot 6$ & 4.5 & 4.6 \\
\hline \multicolumn{9}{|c|}{ Naringenin } \\
\hline 1 & 6 & 5 & $12 \cdot 6$ & $26 \cdot 0$ & $60 \cdot 1$ & $36 \cdot 1$ & $10 \cdot 0$ & $3 \cdot 0$ \\
\hline 2 & 5 & 5 & $6 \cdot 3$ & $19 \cdot 8$ & $10 \cdot 0$ & 38.2 & 1.7 & 3.2 \\
\hline 3 & 4 & 5 & $42 \cdot 0$ & $76 \cdot 8$ & 173.9 & 219.5 & 29.0 & $18 \cdot 3$ \\
\hline 4 & 5 & 5 & 18.4 & $40 \cdot 4$ & 45.4 & 99.7 & 7.6 & $8 \cdot 3$ \\
\hline 5 & 5 & 5 & $9 \cdot 8$ & $15 \cdot 7$ & $19 \cdot 6$ & $29 \cdot 1$ & 3.3 & $2 \cdot 4$ \\
\hline 6 & 5 & 5 & 11.5 & $25 \cdot 4$ & 21.9 & $129 \cdot 3$ & 3.7 & $10 \cdot 8$ \\
\hline 7 & 5 & 5 & $14 \cdot 2$ & 33.9 & $46 \cdot 0$ & 117.5 & $7 \cdot 7$ & $9 \cdot 8$ \\
\hline Mean & $5 \cdot 0$ & $5 \cdot 0$ & $16 \cdot 4$ & 34.0 & 53.9 & 95.6 & $9 \cdot 0$ & 8.0 \\
\hline SD & 0.6 & 0.0 & 11.9 & $20 \cdot 6$ & $55 \cdot 8$ & 68.6 & $9 \cdot 3$ & $5 \cdot 7$ \\
\hline
\end{tabular}

$t_{\max }$, Time taken to reach peak concentration; $C_{\max }$, peak concentration; AUC, area under the curve. 
After the BOJ ingestion, naringenin and hesperetin plasma concentrations increased, reaching a peak at about $5.0 \mathrm{~h}$, indicating that these molecules are absorbed from the distal parts of the small intestine or the colon. After $24 \mathrm{~h}$ the flavanone plasma levels returned to basal values. However, in several subjects, hesperetin and naringenin conjugates soon appeared in plasma $(2-3 \mathrm{~h})$ after consumption of BOJ containing their glycosides, indicating a possible absorption from the proximal part of the small intestine. Some authors have reported flavonoid absorption from the small intestine (Hollman et al. 1999; Walgren et al. 2000) and small-intestinal enzymes able to hydrolyse flavonoid glycosides have also been isolated (Day et al. 1998, 2000). On the other hand, the isolated enzymes were able to hydrolyse several flavonoid glucosides but not naringin. Neither hesperidin, nor its hydrolysis or glucuronidation products, was detected in the lumen after the perfusion of the jejunum and ileum with hesperidin (Spencer et al. 1999). Moreover, after a single oral administration of naringin, intact naringin was isolated after $2-4 \mathrm{~h}$ in human urine (Ishii et al. 2000). This study suggests that a small amount of naringin can be rapidly absorbed from the human gastrointestinal tract. Other studies, involving the absorption of anthocyanins, demonstrated that these flavonoids were rapidly and efficiently absorbed from the stomach (Passamonti et al. 2003; Talavera et al. 2003).

The present results suggest that flavonoid uptake occurs not only in the large intestine, where bacterial enzymes hydrolyse glycosides before absorption of the aglycone, but also in the small intestine; where small amounts of flavonoids can be absorbed.

Hesperetin and naringenin maximum plasma concentrations, after the ingestion of $300 \mathrm{ml} \mathrm{BOJ,} \mathrm{were} \mathrm{in} \mathrm{the}$ range $15-200$ and $15-80 \mathrm{ng} / \mathrm{ml}$, respectively. The results are comparable with those of a study (Manach et al. 2003) carried out using different blond orange juice quantities administered with a meal. Moreover, in an another study (Erlund et al. 2001), the authors reported similar kinetic curves but higher plasma hesperetin concentrations ranging from 150 to $1500 \mathrm{ng} / \mathrm{ml}$ after the ingestion of blond orange juice providing about $125 \mathrm{mg}$ hesperetin. On the other hand, other studies on flavonoid bioavailability in human subjects report plasma concentrations comparable with those found in the present study (Manach et al. 2005b).

In BOJ, the hesperidin concentration was about eight times that of narirutin, so it is not surprising that the naringenin concentrations found in plasma were lower than those of hesperetin. However, for naringenin, the $\mathrm{AUC}_{0-24 \mathrm{~h}} / \mathrm{mg}$ ingested flavanones ratio was higher than for hesperetin as previously observed by Franke et al. (2005). This seems to indicate that naringenin was more bioavailable than hesperetin.

In conclusion, the present study describes the pharmacokinetics of hesperetin and naringenin in human subjects and provides evidence that the concentrations in plasma rapidly return to their basal values. For this reason it is important to have a habitual intake of BOJ to have a possible health benefit.

\section{References}

Choudhury R, Chowrimootoo G, Srai K, Debnam E \& Rice-Evans CA (1999) Interactions of the flavonoid naringenin in the gastrointestinal tract and the influence of glycosylation. Biochem Biophys Res Commun 265, 410-415.
Day AJ, Canada FJ \& Diaz JC (2000) Dietary flavonoid and isoflavone glycosides are hydrolyzed by the lactase site of lactase phlorizin hydrolase. FEBS Lett 468, 166-170.

Day AJ, DuPont MS \& Ridley S (1998) Deglycosylation of flavonoid and isoflavonoid glycosides by human small intestine and liverglucosidase activity. FEBS Lett 436, 71-75.

Edmunds KM, Holloway AC, Crankshaw DJ, Agarwal SK \& Foster WG (2005) The effects of dietary phytoestrogens on aromatase activity in human endometrial stromal cells. Repr Nutr Dev 45, 709-720.

Erlund I, Meririnne E, Alfthan G \& Aro A (2001) Plasma kinetics and urinary excretion of the flavanones naringenin and hesperetin in humans after ingestion of orange juice and grapefruit juice. J Nutr 131, 235-241.

Felgines C, Talavera S, Texier O, Gil-Izquierdo A, Lamaison JL \& Remesy C (2000) Bioavailability of the flavanone naringenin and its glycosides in rats. Am $J$ Physiol 279, G1148-G1154.

Franke AA, Cooney RV, Henning SM \& Custer LJ (2005) Bioavailability and antioxidant effects of orange juice components in humans. J Agric Food Chem 53, 5170-5178.

Harris DM, Besselink E, Henning SM, Go VLW \& Heber D (2005) Phytoestrogens induce differential estrogen receptor $\alpha$ - or $\beta$-mediated responses in transfected breast cancer cells. Exp Biol Med 230, 558-568.

Heo HJ, Kim DO, Shin SC, Kim MJ, Kim BG \& Shin DH (2004) Effect of antioxidant flavanone, naringenin, from Citrus junos on neuroprotection. J Agric Food Chem 52, 1520-1525.

Hirata A, Murakami Y, Shoji M, Kadoma Y \& Fujisawa S (2005) Kinetics of radical-scavenging activity of hesperetin and hesperidin and their inhibitory activity on COX-2 expression. Anticancer Res 25, 3367-3374.

Hollman PC, Bijsman MN, van Gameren Y, Cnossen EP, de Vries JH \& Katan MB (1999) The sugar moiety is a major determinant of the absorption of dietary flavonoid glycosides in man. Free Rad Res 31, 569-573.

Ishii K, Furuta T \& Kasuya Y (2000) Mass spectrometric identification and high-performance liquid chromatographic determination of a flavonoid glycoside naringin in human urine. J Agric Food Chem 48, 56-59.

Justesen U, Knuthsen P \& Leth T (1997) Determination of plant polyphenols in Danish foodstuffs by HPLC-UV and LC-MS detection. Cancer Lett 114, 165-167.

Kanaze FI, Bounartzi MI, Georgarakis M \& Niopas I (2006) Pharmacokinetics of the citrus flavanone aglycones hesperetin and naringenin after single oral administration in human subjects. Eur $J$ Clin Nutr, Published online: 18 October 2006; DOI:10.1038/ sj.ejcn.1602543.

Kuhnau J (1976) The flavonoids. A class of semi-essential food components: their role in human nutrition. World Rev Nutr Diet 24, 117-191.

Kurowska EM \& Manthey JA (2004) Hypolipidemic effects and absorption of citrus polymethoxylated flavones in hamsters with diet-induced hyper-cholesterolemia. J Agric Food Chem 52, 2879-2886.

Le March L (2002) Cancer preventive effects of flavonoids - a review. Biomed Pharmacother 56, 296-301.

Manach C, Mazur A \& Scalbert A (2005a) Polyphenols and prevention of cardiovascular diseases. Curr Opinion Lipidology 16, 77-84.

Manach C, Morand C, Gil-Izquierdo A, Bouteloup-Demange C \& Remesy C (2003) Bioavailability in humans of the flavanones hesperidin and narirutin after the ingestion of two doses of orange juice. Eur J Clin Nutr 57, 235-242.

Manach C, Scalbert A, Morand C, Rémésy C \& Jimenez L (2004) Polyphenols: food sources and bioavailability. Am J Clin Nutr 79, $727-747$. 
Manach C, Williamson G, Morand C, Scalbert A \& Rémésy C (2005b) Bioavailability and bioefficacy of polyphenols in humans. I. Review of 97 bioavailability studies. Am J Clin Nutr 81, 230-242.

Matsumoto H, Ikoma Y, Sugiura M, Yano M \& Hasegawa Y (2004) Identification and quantification of the conjugated metabolites derived from orally administered hesperidin in rat plasma. $J$ Agric Food Chem 52, 6653-6659.

Matuszewski BK, Constanzer ML \& Chavez-Eng CM (2003) Strategies for the assessment of matrix effect in quantitative bioanalytical methods based on HPLC-MS/MS. Anal Chem 75, 3019-3030.

Morrissey C \& Watson RW (2003) Phytoestrogens and prostate cancer. Curr Drug Targets 4, 231-241.

Nielsen ILF, Chee WSS, Poulsen L, Offord-Cavin E, Rasmussen SE, Frederiksen H, Ensen M, Barron D, Horcajada M-N \& Willimson $\mathrm{G}$ (2006) Bioavailability is improved by enzymatic modification of the citrus flavonoid hesperidin in humans: a randomized, double blind, crossover trial. J Nutr 136, 404-408.

Passamonti S, Vrhovsek U, Vanzo A \& Mattivi F (2003) The stomach as a site for anthocyanins absorption from food. FEBS Lett 544, 210-213.

Pietta PG, Simonetti P, Roggi C, Brusamolino A, Pellegrini N, Maccarini L \& Testolin G (1996) Dietary flavonoids and oxidative stress. In Natural Antioxidants and Food Quality in Atherosclerosis and Cancer Prevention, pp. 249-255 [JT Kumpulainen and JT Salonen, editors]. Cambridge: Royal Society of Chemistry.

Riso P, Visioli F, Gardana C, Grande S, Brusamolino A, Galvano F, Galvano G \& Porrini M (2005) Effects of blood orange juice intake on antioxidant bioavailability and on different markers related to oxidative stress. J Agric Food Chem 53, 941-947.
Robards K, Li X, Antolovich M \& Boyd S (1997) Characterization of citrus by chromatographic analysis of flavonoids. J Sci Food Agric 75, $87-101$.

Rotelli AE, Guardia T, Juarez AO, de la Rocha NE \& Pelzer LE (2003) Comparative study of flavonoids in experimental models of inflammation. Pharm Res 48, 601-606.

Sampson L, Rimm E, Hollman PC, de Vries JH \& Katan MB (2002) Flavonol and flavone intakes in US health professionals. $J$ Am Diet Assoc 102, 1414-1420.

Scalbert A, Manach C, Morand C, Remesy C \& Jimenez L (2005) Dietary polyphenols and the prevention of diseases. Critical Rev Food Sci Nutr 45, 287-306.

Shen SC, Ko CH, Tseng SW, Tsai SH \& Chen YC (2004) Structurally related antitumor effects of flavanones in vitro and in vivo: involvement of caspase 3 activation, p21 gene expression, and reactive oxygen species production. Toxicol App Pharm 197, 84-95.

Spencer JP, Chowrimootoo G, Choudhury R, Debnam ES, Srai SK \& Rice-Evans C (1999) The small intestine can both absorb and glucuronidate luminal flavonoids. FEBS Lett 458, 224-230.

Talavera S, Felgines C, Texier O, Besson C, Lamaison JL \& Remesy C (2003) Anthocyanins are efficiently absorbed from the stomach in anaesthetized rats. J Nutr 133, 4178-4182.

Tomas-Barberan FA \& Clifford MN (2000) Flavanones, chalcones and dihydrochalcones - nature, occurrence and dietary burden. J Sci Food Agric 80, 1073-1080.

Walgren RA, Lin JT, Kinne RK \& Walle T (2000) Cellular uptake of dietary flavonoid quercetin $4^{\prime}-\beta$-glucoside by sodium-dependent glucose transporter SGLT1. J Pharmacol Exp Ther 294, 837-843. 